\title{
Comic Function in the Animated Ecodiscourse (Case Study of "Zootopia")
}

\author{
Natalia Ivchenko \\ Department of English Philology, V.N. Karazin Kharkiv National University, Kharkiv, Ukraine
}

\begin{abstract}
This study focuses on the role of comic functions in exposing and challenging hidden ideologies, intentions, potential significance and other phenomena behind the animated ecological discourse of the film "Zootopia". The paper consistently considers two views on the ecology of animated discourse and comic functions that are used to uncover violation and establish an eco-friendly relation by means of language forms. The material of the English-language animated discourse of the film "Zootopia" examines cooperation of verbal and nonverbal modes, exposes problems and encourages solving them as well as promotes establishment of sustainable relationships between humans themselves, humans and nature as well as its phenomena.
\end{abstract}

Index Terms - animated discourse, comic, ecolinguistics, mode, multimodality, Zootopia

\section{INTRODUCTION}

Ecolinguistics is a modern science that focuses on discovering language means that encourage eco-friendly interaction with and about nature. Ecolinguists Alexander and Stibbe (2014, p. 104) gave a very detailed definition of ecolinguistics as "the study of the influence of language on the life-support relationship between human beings, other organisms and the physical environment. In other words, ecolinguistics focuses on how language forms, maintains, influences or destroys the relationship between human beings, other forms of life and the environment." Lingvoecological analysis of comic animated discourse is constrained to attract attention to ecological problems, reveal hidden ideologies, ideas, stereotypes and propaganda behind discourse. Arran Stibbe (2015) classifies discourses into three categories: beneficial, ambivalent and destructive discourses.

In our study, we consider the comic animated discourse "Zootipia" as a beneficial ecological discourse because it is favourable to humans, nature as well as animals. The main characters of "Zootopia" are anthropomorphic animals who help the viewer to put animals at the same level as humans and show that both are an equal part of nature.

Comic animated discourse exists between real and fiction worlds. The fictional side of animated discourse is represented by an alternative view on animals as it shows them very human-like. They can speak, walk on hind legs, wear clothes, have work and act in different situations, which breaks the wall between humans and animals by using the same words and language constructions. The real world in this type of discourse is represented by stereotypes, interests, ideologies, facts and ecological problems. Comic animated discourse directly, metaphorically or hyperbolically reproduces various cultural phenomena and stereotypes of society.

This paper is an attempt to explore how the language in the animation "Zootopia" influences people's attitudes towards various things and phenomena of the world, thus shaping behaviour, beliefs, reactions and interactions of the viewers.

\section{THEORETICAL PREREQUISITES}

Animated discourse is a communicative system that is a complex semiotic structure, which is formed by different modes, which are viewed in the context of multimodality. The latter is a term that has recently been coined within the realms of media studies (Peeters, 2010, p. 104) to account for discourse forms in which the borders between the linguistic and non-linguistic levels or modes are transcended. Furthermore, through its focus on the effects of discourse on people, the concept of multimodality may explicate ecological functions of the animated discourse.

Mode is a part of a multidimensional communicative network (Bay et Al., 2003, p. 37). "This mode of modality could be coined by way of integrative multimodality. The perfect example would be an animated discourse, where video, dialogue voices, sounds, music and subtitles are attuned to such a degree that the viewer does not notice them as separate entities anymore, but rather sees them as part of the reality of the discourse" (Peeters, 2010, p. 123). To put it more simply, the mode is an information transmission channel which authors use to fully implement ideas, ideologies and conceptions about ecological issues or manipulate the viewer's opinion.

The two main modes shape the content of animated discourse. Firstly, the verbal mode forms the linguistic system of the film (character speech, voice-over, captions, titles, inscriptions, street names, cities, etc., which are part of the world of a film). Secondly, the nonverbal mode includes the non-linguistic system of the animated discourse: visual mode (visual images, character movements, distance between them, scenery, scene, shot angle, the size ratio of the objects) 
and audio or sound mode (the way they speak, i.e. prosody of the characters and voiceovers, natural noises, music, songs, etc.).

Animated discourse may be considered ecological due to two definitions. The first one, stated by Ivanova is as follows: "The ecological discourse is any set of statements and texts about existence and interaction of humans with other living organisms between each other and with the environment" (Ivanova, 2015). In other words, ecolinguistics deals not only with investigations made by ecologists but also takes into consideration all kinds of research that in one way or another covers ecological problems and speaks about natural phenomena. According to the second point of view, animated discourse can be considered ecological if it performs ecological functions. Stibbe maintains that ecolinguistics is simply "the use of techniques of linguistic analysis to reveal the stories-we-live-by, opening them up to question and challenge from an ecological perspective" (Stibbe, 2015, p. 5). For instance, animated discourse not only reflects problems of the real world but also challenges them through the comic.

Comic is a breakthrough in the essence, truth and fundamental eternal human value (Samokhina, 2012, p.7). We would add, it is not only a way of life but a way of surviving. Don and Alleen Nilsen (2019, p. 23) also claim that comic can be used to bond people in a social group, teach concepts, make people relieve stress, may encourage to investigate the nature of things, may require people to view issues from various perspectives.

Using comic people "look for and find the superiority or hostility aspects of humour, or the incongruity and incongruity resolution aspects of humour, or the release and relief aspects of humour" (ibid., p. 24). Comic components exist in all spheres of life, even in such strict and serious aspects as politics, medicine and ecology. It is the only story that has the "courage" to talk about all aspects of life (Stibbe, 2015, p. 5). Therefore, its subjects may even include discrimination, racism, ecological issues that people are not supposed to joke about.

Comic "is based on violation of immutable rules (linguistic, pragmatic and social), which are an integral part of the human worldview" (Samokhina, 2012, p. 183). The ecological essence of comic is violation of norms, stereotypes, clichés, etc. Due divergence from a norm in humour a new ecologically friendly norm is created which is considered the norm of comic perception of the world [ibid.]. "Comic blurs boundaries between real and imaginary world, violates established norms and laws that hinder ecology, thus promoting it. In a comic situation, a person intuitively comprehends the discrepancy between the inferior, imperfect and non-ecological content of a phenomenon and its form which claims to be complete, significant and environmentally friendly" [ibid.]. The viewer understands the difference between a high goal - promotion of the ecological attitude towards the world and its phenomenon by absurd, preposterous and ludicrous means of uncovering non-ecological sense.

Therefore, comic is a unique phenomenon whose ecological competencies function most vividly in animated discourse. A bright and quirky world of animation allows the author or authors to embody the bravest ideas. Some comic functions classified by Samokhina (2012), may also perform purely ecological functions in animated discourse: the entertaining function - ecological aim of which is to make people laugh, relax, distract from everyday life so that the problems of real world not to interfere with perception of the information revealed by other functions. In other words, this function creates favourable conditions to immerse oneself in funny world of animation and acquire information from it correctly; the phatic function - establishes eco-friendly comic contact or maintains it; the attractive function - the purpose of which is to draw the viewer's attention to ecological problems in comic animated discourse; the regulatory function - comic is a kind of evaluation of behaviour of members of society (good laughter motivates, and bad laughter shows that something is wrong), so it regulates behavioural eco-friendliness; the critical function - encourages critical thinking and attitude to the facts concealed in discourse. The critical function maintains healthy attitude and can assist the exposing function; the exposing function - comic may violate norms, stereotypes, etc., thereby revealing their obsolescence, inappropriateness and environmental (un)friendliness; the function of detabuization allows authors to express their thoughts and feelings on issues more loosely preserving the ecology of communication (in particular, with the help of characters from animated discourse); the masking function provides the author with the opportunity to mask (which does not mean to cover or conceal, as information is to be seen and understood) any information in order to transmit it in a gentle ecological way; the function of self-affirmation - comic enables ecological creative development of both authors and viewers; the adaptive function - comic helps a person to adapt more easily to the conditions of the world, so as not to harm the world; the distracting function - is a distracting manoeuvre that prevents people from wasting energy on things that are not worth it and may be harmful to the person and ecological world.

Broadly speaking, a comic component excavates hidden information, reveals language power and shows how language may become the tool of ecology. So, the authors' choice of language means is not some obituary decision. "The reason why a particular text expresses a particular meaning is the result of the choice of a speaker or creator. In many cases, the speaker's choice of a language form is cautious, purposeful and conscious, because only by choosing the suitable form can the proper meaning be expressed; while in other cases, the speaker's choice of linguistic form is subconscious or even unconscious" (Zuo, 2019, p. 40). However, whether this choice is conscious or not, it needs to be investigated by what method the meaning in discourse is built and by what means encourage a healthy emotional connection between humans and nature. 


\section{Methodology}

The methodological background of this work is an ecological discourse analysis, which helps to improve sustainability of communication in social ecosystems employing a multimodal approach which takes into account verbal and nonverbal modes, as well as national and cultural specifics of discourse. The discursive approach to the comic animated ecodiscourse allows to study particular qualities of its implementation and considers comic functions, such as entertaining, attractive, regulatory, critical, exposing, masking, adaptive, distracting as well as the function of self-affirmation and detabuization, The integrative nature of the study requires a number of specific cooperating methods, the most important are ecological discourse analysis, intent analysis and, the method of cognitive modelling which benefits the study cognitive mechanism of incongruity.

The study tries to explore how the language, modes and comic components of the animation "Zootopia" help the author express his thoughts, ideas and attitudes towards nature and its phenomena and show how the choice of verbal and non-verbal means may influence the viewer's relationship with other people and natural phenomena.

The current study is based on the 108-minute animation "Zootopia" from which we have chosen 5 extracts which vividly demonstrate how comic functions explore stereotypes, ideas and ecological problems behind comic animated discourse and help the viewer to establish sustainable attitude towards other people, natural world and its phenomena.

\section{SOME PREliminary REMARKS ON THE ANIMATION “ZOOTOPIA”}

"Zootopia" (Howard \& Moore, 2016) is an American computer-animated comedy-adventure film produced by Walt Disney Animation Studios and released by Walt Disney Pictures (Zootopia WIKI). It was created by Byron Howard and Rich Moore, co-directed by Jared Bush and has a record box office success in several countries. It became the 25th film that crossed the $\$ 1$ billion milestones. In 2017, the film won an Oscar for the nomination "Best Animated Feature Film". The film was chosen by the American Film Institute as one of the top ten films of 2016 and won the Academy Award, Golden Globe, Critics Choice Movie Award and Annie Award for Best Animated Feature Film and received a nomination for the BAFTA Award for Best Animated Film (Zootipia).

The film tells about Zootopia - a modern city inhabited by different animals, from huge elephants to tiny shrews. Zootopia is divided into areas that completely overlap the natural habitat of different animals. The film's coverage of the hot topics of prejudice, stereotypes, social and environmental issues earned critical acclaim. Zootopia constantly asks its characters to look past species stereotypes, and not to use the "speciesist" language or repeat harmful assumptions (Seitz, 2016). In other words, it teaches viewers not to be a racist, not to use the racist language, not to be biased, and not to believe in prejudice and stereotypes. It stimulates people to establish healthy, positive and eco-friendly relations with other people, nature and its phenomena.

\section{RESEARCH AND DISCUSSION}

Scene 27 "Assistance from Bellwether" (Howard \& Moore, 2016) presents the viewer with more information about Assistant Mayor Bellwether who is "underestimated, underappreciated" (as she claims later in the film) by predators. The comic component in this scene performs several ecological functions. First, the comic highlights ambiguous information which is explicated by the attractive function - entertaining the viewer. Dawn Bellwether is a sheep, therefore her swearing in the following example (e.g. 1, underlined) encourages the viewer's attention:

(1) Leodore Lionheart: Okay! I heard you, Bellwether, just take care of it! Please. And clear my afternoon, I'm going out.

Dawn Bellwether: Oh, no, but sir, you do have a meeting with Herds and Grazing, sir, if I can just...! Oh, mutton chops. (Zootopia: time step: 01:00:53 - 01:01:08; Howard \& Moore, 2016)

The authors must have intentionally put this ambiguous swearing (e.g. 1, underlined) where "mutton" means meat from an adult sheep eaten as food, and "chop" is a small piece of meat with a bone still in it. These meanings imply cruelty towards sheep though the swearing creates a comic effect being used by one of them. This attracts the viewer's attention to the situation and especially to her outfit which is "ironically made of wool" (Bellwether). On the other side, "muttonchops" - in one word, stands for "side-whiskers that are narrow at the temples and broad and trimmed short at the jawline, the chin being shaved both in front and beneath" (Muttonchops). This meaning is supported by the visual mode of the animation - Mayor of Zootopia wears muttonchops (Fig.1) which hints that Bellwether may address the Mayor. The comic encourages critical thinking in order to solve this ambiguity. Also, the last meaning suggests the allusion to the saying describing the relationship of the Mayor and his assistant "In like a lion, out like a lamb" which provides an adaptive function, that helps the viewer understand the animation in general. 


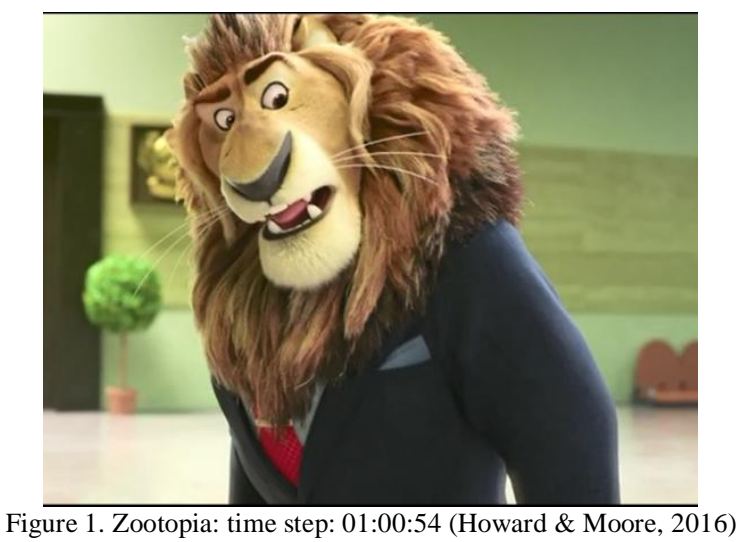

Later, in the same scene, Assistant Mayor is helping the main character Officer Judy Hopps and her civil assistant Nick Wild with their case:

(2) Dawn Bellwether: I mean, you know, I never get to do anything this important.

Judy Hopps: But you're the assistant mayor of Zootopia.

Dawn Bellwether: Oh, I'm more of a glorified secretary. I think Mayor Lionheart just wanted the sheep vote.

But he did give me that nice mug. Feels good to be appreciated. (Zootopia: time step: 01:01:42 - 01:01:57; Howard \& Moore, 2016)

The name "Bellwether" is used in attractive and adaptive functions. It attracts attention to several oxymorons in example 2 and explains them in order to help the viewer understand the hidden meaning in animation. The former part of the last name "Wether" means "a castrated male sheep, bred only for meat" (Bellwether). This explains the first oxymoron "never get to do anything this important" - "But you're the assistant mayor" which is quite strange as her position must be very important in the city, but she still feels underappreciated. Also, the whole last name supports verbal mode "Lionheart just wanted the sheep vote", as the term "Bellwether" refers to a "sheep that leads a herd" (ibid). Therefore, it can be seen from the name that Mayor hired the sheep only to manipulate the voters - so, the comic name and the verbal mode detabuizes not only discrimination of the sheep (women) but also the problem of unfair elections. At this point, we should recall the names mentioned in example 3 "Herds and Grazing", the former last name has the root "herd" which means a group of animals and the latter - land where farm animals feed on grass. This implies that the lion asks his assistant to cancel meetings with some farm animals, most probably sheep.

The next comic oxymoron is built on the incongruity of the visual (Fig. 2) and verbal modes: the sheep says that she is "a glorified secretary" and "good to be appreciated" which is a hyperbole and hidden sarcasm. The visual mode shows the mug that says "World's greatest dad assistant mayor" presented to the sheep by the lion. The above mentioned implies two possible surmises. The first is that the Lion underappreciated his children's gifts and the second is that his assistant uses the mug to store writing tools in her office where no one sees it. The above stated utterance opposes the verbal mode and enhances the comic functions of critical thinking and regulatory function as it regulates the attitude to the situation and supports rethinking.

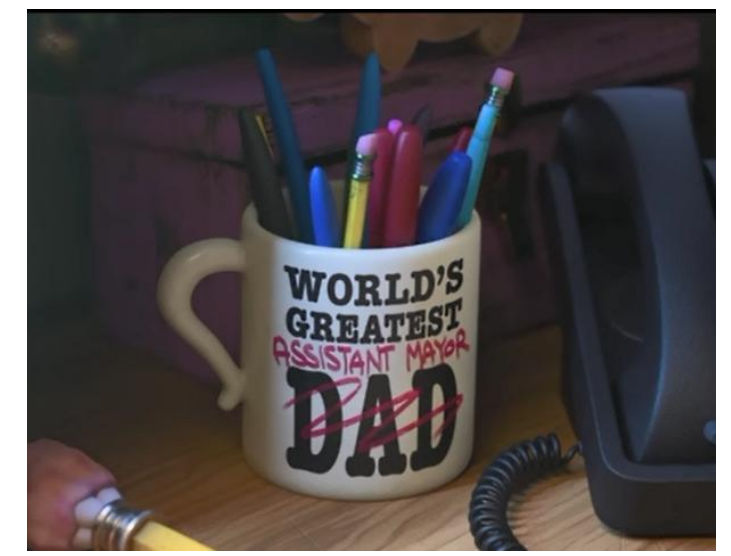

Figure 2. Zootopia: time step 01:54:01 (Howard \& Moore, 2016)

The second predator the Sheep deals with in the animation is the Fox who helps the main character to investigate the case. The visual mode shows that they don't interact as "human beings" at all. The fox treats her as an object:

(3) Nick Wilde: So fluffy!

Judy Hopps: Hey!

Nick Wilde: Sheep never let me get this close. 
Judy Hopps: You can't just touch a sheep's wool!

Nick Wilde: It's like cotton candy!

Judy Hopps: Stop it! (Zootopia: time step: 01:01:20 - 01:01:33; Howard \& Moore, 2016)

This example demonstrates that the predator treats the prey like an object. He touches her wool and notes that it is "So fluffy" - something soft which describes characteristics of an object, not a person. Though the word "fluffy" has a slang meaning - "usually describing a person or behaviour that is soft, cute and anything unmanly normally seen as an insult or an embarrassment" [Peckham], and this meaning is also offensive. The fox pays attention only to her wool and uses the description "cotton candy" which denotes a type of food. These meanings are supported visually as the fox looks very excited touching her wool (Fig. 3). Collaborating the modes create the comic effect and perform the exposing function, the Fox's behaviour turns out to be very offensive thus he means well.

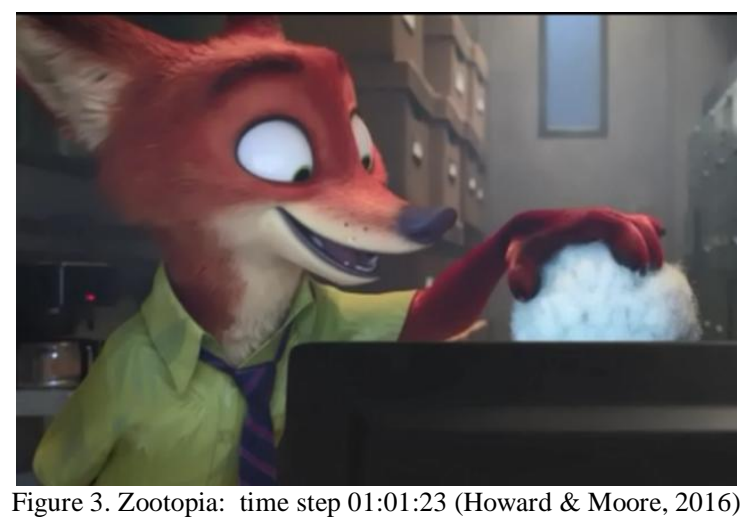

The authors in this scene also use allusion to the famous mental exercise before sleeping "Nick Wilde: You think when she goes to sleep, she counts herself?" (Howard \& Moore, 2016). The situation appears absurd, the comic effect encourages the viewer to critical thinking. The practice has been so commonly referenced by cartoons and other mass media and has become deeply integrated into the stereotypical notion of sleep. Medical studies show that it is no more than a stereotype as "insomniacs in the group that had to count sheep took longer than usual to fall asleep" (Stibich 2019). So, this scene teaches the viewer not to believe stereotypes and appreciate both people and animals for who they are and the work they do.

Another bright example is presented in scene 23: "Nick's Childhood" (Howard \& Moore, 2016). In this scene, the Fox Nicolas Wild tells a story as he tried to become a member of The Junior Ranger Scouts (group of young prey mammals in Zootopia) (Junior Ranger Scouts):

(4) Nick Wilde: No, it's true. I think I was eight or maybe nine, and all I wanted to do was join the Junior Ranger Scouts. So, my mom scraped together enough money to buy me a brand new uniform because by God I was gonna fit in, even if I was the only predator in the troop, the only fox.

Woodchuck Boy: Okay, Nick.

Nick Wilde: I was gonna be part of a pack. (Zootopia: time step: 00:58:18 - 00:58:44; Howard \& Moore, 2016)

Above all, the character's last name implements a critical function. "Wilde", is a play on the word "wild" which conflicts with the context of the animation. Nick lives in Zootopia city since childhood, so he is not wild, rather social. Furthermore, the verbal mode (e. g. 4, underlined) supports that his childhood dream was to "fit in" in a social pray organisation despite being a predator. In his speech, Nick uses three synonymic phrases "I was gonna fit in", "even if I was the only predator in the troop, the only fox", "I was gonna be part of a pack" (Howard \& Moore, 2016) in order to highlight that he was not prejudiced then. Still, in the latter phrase, he uses the word "pack" which commonly describes a group of predator animals.

(5) Woodchuck Boy: Okay. Now raise your right paw and deliver the oath.

Young Nick Wilde: I, Nicholas Wilde, promise to be brave, loyal, helpful and trustworthy!

Woodchuck Boy: Even though you're a fox?

Young Nick Wilde: What? No, no! What did I do wrong, you guys? No, please! Tell me what did I do wrong? What did I do? Gah!

Woodchuck Boy: If you thought we would ever trust a fox without a muzzle, you're even dumber than you look. Nick Wilde: I learned two things that day. One: I was never gonna let anyone see that they got to me.

Judy Hopps: And two?

Nick Wilde: If the world's only gonna see a fox as shifty and untrustworthy, there's no point in trying to be anything else. (Zootopia: time step: 00:58:52 - 01:00:03; Howard \& Moore, 2016)

This example presents incongruity between the oath given by the Fox "brave, loyal, helpful and trustworthy" and the common stereotype about foxes - sly, "shifty and untrustworthy" as Nick mentions himself which performs two functions. The first is the exposing function which shows that unprejudiced Fox turns out to be a victim of prejudiced prays who bullied and muzzled him. This function is intensified by a visual mode (Fig. 4) as Nick looks smaller than 
prays even the woodchuck who is much smaller than foxes in the real world. The second is the function of detabuization as authors imply the problem of discrimination and do not interfere ecology of communication with the viewer. They encourage the viewer to come to a conclusion that is incongruous to Nick's that under such circumstances "there's no point in trying to be anything else", where he uses the negative words (underlined). The verbal mode supports it as the main character, using positive lexis, implies "Judy Hopps: Nick, you are so much more than that" (Zootopia: time step: 01:00:03 - 01:00:08; Howard \& Moore, 2016). So, the authors in this scene teach the viewer not to be prejudiced and follow your dreams even if it seems the whole world is against you.

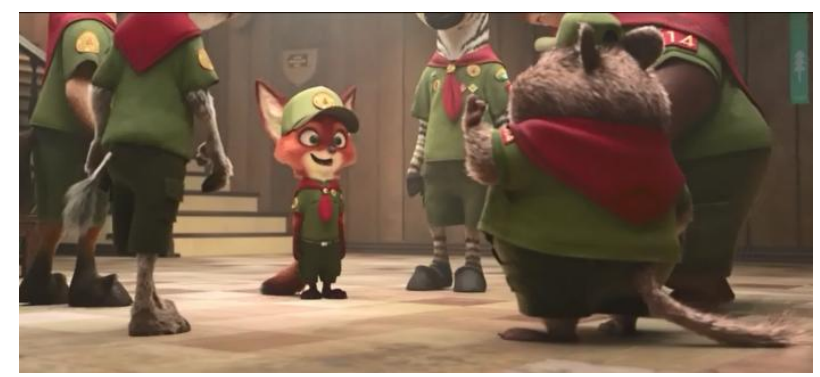

Figure 4. Zootopia: time step 00:58:48 (Howard \& Moore, 2016)

The comic component appearing in different modes performs a set of ecological functions. First of all, it entertains and helps the viewer to relax from the routine and problems, in this way preparing the viewer to the perception of further information. It helps the viewer employing animation understand the world they are living in, think over or rethink some behaviour, attitudes and beliefs and learn how to deal with the world in an ecologically friendly way. On the other hand, it provides the author with the opportunity to express their thoughts and ideas more freely by masking (not hiding and one of the main comic functions is to expose) them under zoomorphic animals. The comic component also attracts attention to the problems stated in comic animated ecodiscourse, exposes them and encourages critical thinking.

\section{CONCLUSION}

Comic animation discourse teaches the viewer both young and adult about the values, such as the value of life, both human life and the life of other animals and plants, nature value and social value, the role and value of diversity and biodiversity.

Broadly speaking, the ecological comic functions in animated discourse cooperating with the verbal and non-verbal modes provide authors with the opportunity to express their ideas and thoughts even on such topics as discrimination, racism and environmental problems more freely. At the same time, they help the viewer relax, entertain and stimulates positive exploration of the world of comic animated ecodiscourse, attract attention to important facts and issues, maintain an intellectual and rational understanding of verbal, visual and audial information. Through the prism of animated discourse, ecological comic functions show the problems of real world, help the viewer adapt to them and discover possible solutions. Moreover, the functions motivate for eco-friendly relation between human beings and natural phenomena, support ecological creative development and distract from harmful and destroying ideas, attitudes and behaviours.

The ecological comic functions display the language means that encourage, maintain and influence eco-friendly communication, behaviour and warn about linguistic means that destroy or discourage from eco-friendly communication, behaviour and contribute non-ecological ones.

\section{REFERENCES}

[1] Alexander, Richard. \& Stibbe, Arran. (2014). From the analysis of ecological discourse to the ecological analysis of discourse Language Sciences, 41,104-110. doi:10.1016/j.langsci.2013.08.011.

[2] Bay, D., Döör, J., \& Steffensen, S. V. (2003). Modality, Ecology, Metaphor. metaphorik.de, 4, 30-44.

[3] Bellwether. (n.d.). The Disney Wiki. https://disney.fandom.com/wiki/Bellwether (accessed 11/07/2021).

[4] Muttonchops. (n.d.). Dictionary. https://www.dictionary.com/browse/muttonchops (accessed 29/07/2021).

[5] Howard, B., \& Moore, R. (Directors) (2016). Zootopia [Motion Picture]. United States: Walt Disney Studios.

[6] Ivanova, E.V. (2015). Лингвокогнитивное моделирование экологического дискурса [Linguocognitive modeling of ecological discourse]. Moscow: Flinta.

[7] Junior Ranger Scouts. (n.d.). Zootopia Wiki. https://zootopia.fandom.com/wiki/Junior_Ranger_Scouts (accessed 11/07/2021).

[8] Nilsen, D. L., \& Nilsen, A. P. (2018). The language of humour: An introduction. Cambridge: Cambridge University Press.

[9] Peckham, A., ed. (n.d.). Fluffy. Urban Dictionary. https://www.urbandictionary.com/define.php?term=fluffy_(accessed 11/07/2021).

[10] Peeters, H. (2010). Multimodality and its modes in novelizations. Image \& Narrative, 11(1), 118-129. 
[11] Samokhina, V. O. (2012). Жарт y сучасному комунікативному просторі Великої Британії та США: монографія [Јоke in the modern communicative space of Great Britain and the United States: monograph]. View. 2nd, ref. i add. Kharkiv: V. N. Karazin Kharkiv National University.

[12] Seitz, M. (2016) Zootopia movie review \& film summary Rogerebert.com. https://www.rogerebert.com/reviews/zootopia-2016 (accessed 11/07/2021).

[13] Stibbe, A. (2015). Ecolinguistics: Language, ecology and the stories we live by. New York: Routledge.

[14] Stibbe , A. (2015). Ecolinguistics: Language, Ecology and the Stories We Live By. London and New York: Routledge.

[15] Stibich, M. (2019). Does Counting Sheep Put a Person to Sleep? Very Well Health. https://www.verywellhealth.com/doescounting-sheep-actually-put-a-person-to-sleep-2224296 (accessed 11/07/2021).

[16] Zootopia (n.d.). https://www.imdb.com/title/tt2948356/?ref_=tttr_tr_tt (accessed 11/07/2021).

[17] Zootopia WIKI. (n.d.). https://zootopia.fandom.com/wiki/Zootopia_Wiki (accessed 29/07/2021).

[18] Zuo, X. (2019). An Ecological Analysis of Emily Dickinson's "The Grass". Theory and Practice in Language Studies, 9 (7), 849-853. doi:10.17507/tpls.0907.15.

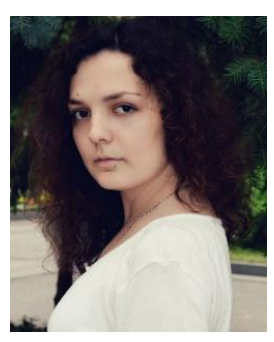

Natalia Ivchenko was born in Kharkiv, Ukraine. She received her master's degree in English Philology from V. N. Karazin Kharkiv National University (Ukraine).

She is currently a PhD student and lecturer of the English Philology Chair, School of Foreign Languages at V. N. Karazin Kharkiv National University (Ukraine). The main research interests include ecolinguistics, discourse analysis, media linguistics and linguistic comic studies. 